\title{
Indução de brotações em matrizes de Acacia mearnsii De Wildeman em relação a idades e quatro estações do ano
}

\author{
Shoots induction of Acacia mearnsii De Wildeman in stock plants at two \\ ages over the seasons of the year
}

\author{
Mara Luana Engel ${ }^{1}$, Giovana Bomfim de Alcantara ${ }^{1 *}$, Paulo César Flôres Júnior ${ }^{1}$ e \\ Antônio Rioyei Higa ${ }^{1}$
}

\begin{abstract}
RESUMO
A acácia negra (Acacia mearnsii De Wild.) é utilizada como matéria-prima para a indústria de tanino, que é extraído da casca, celulose e pellets, além de contribuir para a recuperação de solos. Existe interesse no desenvolvimento da silvicultura clonal com a espécie, no entanto, há dificuldade de enraizamento adventício. Desta forma, o objetivo do presente trabalho foi avaliar o método de indução de brotações e a altura de corte das árvores de matrizes de três e cinco anos ao longo das estações do ano, visando o rejuvenescimento das brotações. Foram testados três métodos de indução de brotações: decepa, torniquete e inclinação forçada, combinados com cinco alturas de coleta $(0,30 ; 0,40 ; 0,60 ; 1,20$ e 2,0 m), nas quatro estações do ano, com árvores de três e cinco anos. O delineamento experimental foi em blocos casualizados, com 15 tratamentos, quatro repetições e seis plantas por parcela. Após 90 dias da instalação do experimento foram avaliadas a porcentagem de árvores com brotações, número de brotações por árvore e comprimento das três maiores brotações. No inverno a decepa respondeu melhor para porcentagem de árvores com brotações, número de brotações por árvore, já para o comprimento médio das três maiores brotações os métodos mais indicados foram a decepa e o torniquete. As alturas de corte de 1,20 e 2,0 m apresentaram os melhores resultados para quantidade de brotações, assim como o método de torniquete nas estações de primavera, verão e outono. As árvores de três e cinco anos responderam de forma semelhante, não diferindo na porcentagem de árvores com brotações e na quantidade de brotações por árvore.
\end{abstract}

Palavras-chave: rejuvenescimento, propagação vegetativa, silvicultura clonal.

\begin{abstract}
Black wattle (Acacia mearnsii De Wild.) is used as raw material for tannin industry, which is extracted from bark, cellulose and pellets and contribute to recovery of degraded soils. There is interest in the development of clonal forestry with the species, however, there is difficulty of rescue of selected adult trees, resulting in low rooting percentages. This study aimed to evaluate induction methods of shoots at different heights of collection of 3 and 5 year-old donor-plants, in each season of the year, for reinvigoration to woody plants. Were tested three different methods: coppicing, tourniquet and forced inclination of individuals, combined with five different heights of collection $(0.30,0.40,0.60,1.20$ and $2.0 \mathrm{~m})$, in four season of the year, for the ages three and five years of the donor-plants. The experimental design was a randomized complete block, with 15 treatments, four replicates and six plants per plot, distributed in a $3 \times 5$ factorial scheme (three methods and five heights). The evaluations were performed at 90 after the installation of the experiment for percentage of trees with buds, number of buds per tree and average length of the three largest shoots. In the winter the coppicing presented the better response for percentage of trees with buds, number of buds per tree, for average length of shoots per tree the most indicated methods were the coppicing and tourniquet. The induction heights of 1.20 and $2.0 \mathrm{~m}$ presented the best results for shoot quantity, as well as the tourniquet method in the spring, summer and autumn seasons. For the two and five-year old trees no differential response was found for percentage of trees with buds and number of buds per tree.
\end{abstract}

Keywords: rejuvenation, vegetative propagation, clonal forestry.

1. Departamento de Ciências Florestais, Universidade Federal do Paraná - UFPR. Curitiba / PR, Brasil. * Autor correspondente: giobomfim@ufpr.br 
Engel et al. - Indução de brotações em matrizes de Acacia mearnsii

De Wildeman em relação a idades e quatro estações do ano

\section{INTRODUÇÃO}

A acácia negra (Acacia mearnsii De Wild.) assumiu relevante expressão comercial ante as relações internas e externas de mercado estabelecidas pelas empresas do setor florestal. Atualmente, compõe um maciço florestal de aproximadamente 130 mil hectares, estabelecido principalmente em pequenas e médias propriedades rurais (IBÁ, 2016). Esses plantios são fontes de matéria-prima para a indústria de tanino, que é extraído da casca, celulose e pellets, que usam a madeira, entre outras, além de sua contribuição ambiental como recuperadora de solos (FOWLER et al., 1999).

Tradicionalmente, a acácia negra tem sido plantada com mudas originadas de sementes, o que tem gerado heterogeneidade de plantios e baixa produtividade (BECK et al., 1998). Em função disso, o desenvolvimento da silvicultura clonal tem sido uma meta a ser atingida. Atualmente, a clonagem de mudas de acácia negra, por meio da estaquia e miniestaquia ocorrem em escala experimental. Em um estudo com três clones de acácia negra foi verificado que o material genético responde de maneira diferenciada ao enraizamento de miniestacas e o ácido indolbutírico, em concentrações variando de 100 a $6000 \mathrm{mg} \mathrm{L}^{-1}$, não apresentou efeito positivo ao enraizamento (ENGEL et al., 2017). Alguns estudos com a multiplicação in vitro de gemas axilares de acácia negra foram conduzidos (DISARZ; MARTINS-CORDER, 2009).

Embora alguns estudos com a propagação vegetativa de acácia negra tenham sido desenvolvidos ainda existe escassez de protocolos eficientes de clonagem com a espécie. Fato este que tem limitado o desenvolvimento do melhoramento genético da espécie. As estratégias de melhoramento baseiam-se em sua maioria em testes de progênies, os quais são convertidos em pomares de sementes por mudas, com a escassez de formação de pomares de sementes clonais (BORGES JÚNIOR et al., 2004). Neste sentido, busca-se o desenvolvimento de métodos de melhoramento baseados na propagação vegetativa, para isto é imprescindível que se consiga o rejuvenescimento de material adulto, visando assim aumentar o percentual de enraizamento adventício de árvores selecionadas (LIU et al., 2018).

O desenvolvimento da silvicultura clonal envolve diferentes etapas. A primeira é a seleção de matrizes em plantios comerciais ou experimentais, em seguida ocorre a indução e resgate de brotações visando a propagação. Essa etapa consiste no processo de rejuvenescimento do material a ser propagado. Posteriormente, segue a produção das mudas pela indução do enraizamento das estacas e por fim, a etapa de implantação e condução de florestas clonais no campo (LUOGA et al. 2004; SAKAI; SAKAI, 1998).

Após a seleção das árvores superiores, as fases subsequentes referem-se ao seu resgate e multiplicação vegetativa. $O$ resgate de matrizes é caracterizado pela obtenção de material juvenil com capacidade de originar raízes adventícias e, para tanto, é necessária a indução das brotações basais nas árvores selecionadas. Para o sucesso no resgate de matrizes muitas vezes é necessários o rejuvenescimento da planta. O rejuvenescimento refere-se a reversão da maturação da planta ou de partes da planta resultante de tratamentos tais como poda, micropropagação e enxertia seriadas e aplicações de inibidores de crescimento, dentre outros. Neste sentido, brotações que foram rejuvenescidas tendem a apresentar uma melhor resposta ao enraizamento (WENDLING et al., 2014).

A técnica de decepa da árvore superior selecionada tem sido relatado para algumas espécies florestais como adequada ao rejuvenescimento, neste sentido foi testada para Ilex paraguariensis (STUEPP et al., 2016), Eucalyptus benthamii (BACCARIN et al., 2015) e Acacia mearnsii De Wild. (BORGES JÚNIOR et al., 2004; PERRANDO; MARTINS CORDER, 2006). A influência da altura da cepa no desenvolvimento da brotação foi avaliada em árvores adultas de acácia negra, sendo que cortes na maior altura testada, $60 \mathrm{~cm}$ do solo, promoveram elevado índice de rebrota e com melhores resultados na época da primavera (BORGES JÚNIOR et al., 2004). Em um outro estudo com acácia negra foi verificado que corte na altura de 1,2 até $2 \mathrm{~m}$ acima do solo, em indivíduos com quatro anos, apresentaram maior capacidade de rebrota. E a rebrota é estimulada principalmente quando o corte é realizado na época do outono e primavera e que o verão é a época menos adequada para esse procedimento (PERRANDO; MARTINS CORDER, 2006).

Em muitos casos a técnica da decepa não é suficiente para a obtenção de brotações e, dependendo de seu valor genético ou histórico, é necessário empregar métodos especiais de resgate sem o abate da planta matriz. Entre as principais técnicas utilizadas destacam-se o anelamento do caule, o uso do fogo na base da árvore e de galhos podados mantidos em casa de vegetação sob nebulização intermitente, visando a sua brotação para produção de estacas (ALFENAS et al., 2004). Dentre outras técnicas menos usuais está a inclinação da árvore e o torniquete. 
Como existe uma lacuna no desenvolvimento de programas de melhoramento genético de acácia negra, por meio de plantios clonais, devido principalmente a dificuldade de resgate de material adulto selecionado em campo, pois poucos estudos foram conduzidos neste sentido e concentram-se na decepa, torna-se importante comparar este método com outras possíveis técnicas de resgate. O presente estudo objetivou avaliar diferentes técnicas de indução de brotações em árvores adultas de acácia negra, bem como a altura ideal de corte da árvore em cada estação do ano, em duas idades de plantas matrizes, visando o rejuvenescimento e resgate de árvores do campo.

\section{MATERIAL E MÉTODOS}

\section{Caracterização da área de estudo}

Os experimentos de campo foram realizados no município de Cristal, RS. O município está localizado na região da Encosta do Sudeste, com clima do tipo Cfa. As áreas avaliadas em Cristal apresentam altitudes entre 180 e $220 \mathrm{~m}$ acima do nível do mar, relevo com inclinações moderadas e precipitações entre 1.200 a $1.400 \mathrm{~mm}$ (RIO GRANDE DO SUL, 1994).

As médias de temperatura e umidade nos anos do estudo (2015 e 1016) foram de $18,9^{\circ} \mathrm{C} \mathrm{e}$ $1.234 \mathrm{~mm} /$ ano (INMET, 2018). Os experimentos foram instalados nas quatro estações do ano, em julho, setembro e dezembro de 2015 e março de 2016. No inverno de 2015, que compreendeu os meses de junho, julho e agosto a média das temperaturas mínimas foram de $11^{\circ} \mathrm{C}$, das máximas de $18^{\circ} \mathrm{C}$ e a precipitação média de $138 \mathrm{~mm}$. Na primavera de 2015 a média da temperatura mínima dos meses de setembro, outubro e novembro foi de $14{ }^{\circ} \mathrm{C}$ e a máxima de $22^{\circ} \mathrm{C}$, com precipitação média de $140 \mathrm{~mm}$. No verão as médias das temperaturas mínimas nos meses de dezembro/ 2015, janeiro e fevereiro/2016 foram de $19^{\circ} \mathrm{C}$ e máxima de $28^{\circ} \mathrm{C}$, com precipitação de $130 \mathrm{~mm}$. No outono de 2016 as médias de temperaturas mínimas para os meses de março, abril e maio foram de $17^{\circ} \mathrm{C}$, as máximas médias de $24^{\circ} \mathrm{C}$ e a precipitação média de $123 \mathrm{~mm}$.

\section{Indução de brotações de matrizes no campo}

Foram testados três diferentes métodos de indução de brotações: decepa do tronco, uso de torniquete ao redor da casca e inclinação forçada de árvores de acácia negra (Figura 1). Também, foram comparadas a indução das brotações em diferentes alturas da base da árvore, 0,30; 0,40; 0,60; 1,20 e 2,0 m. Esses tratamentos foram aplicados em árvores de três e cinco anos, provenientes de mudas seminais, plantadas em um espaçamento de $3 \times 1,75 \mathrm{~m}$, com adubação realizada no primeiro ano de implantação com 50 g/cova da fórmula 5-30-15 (NPK).

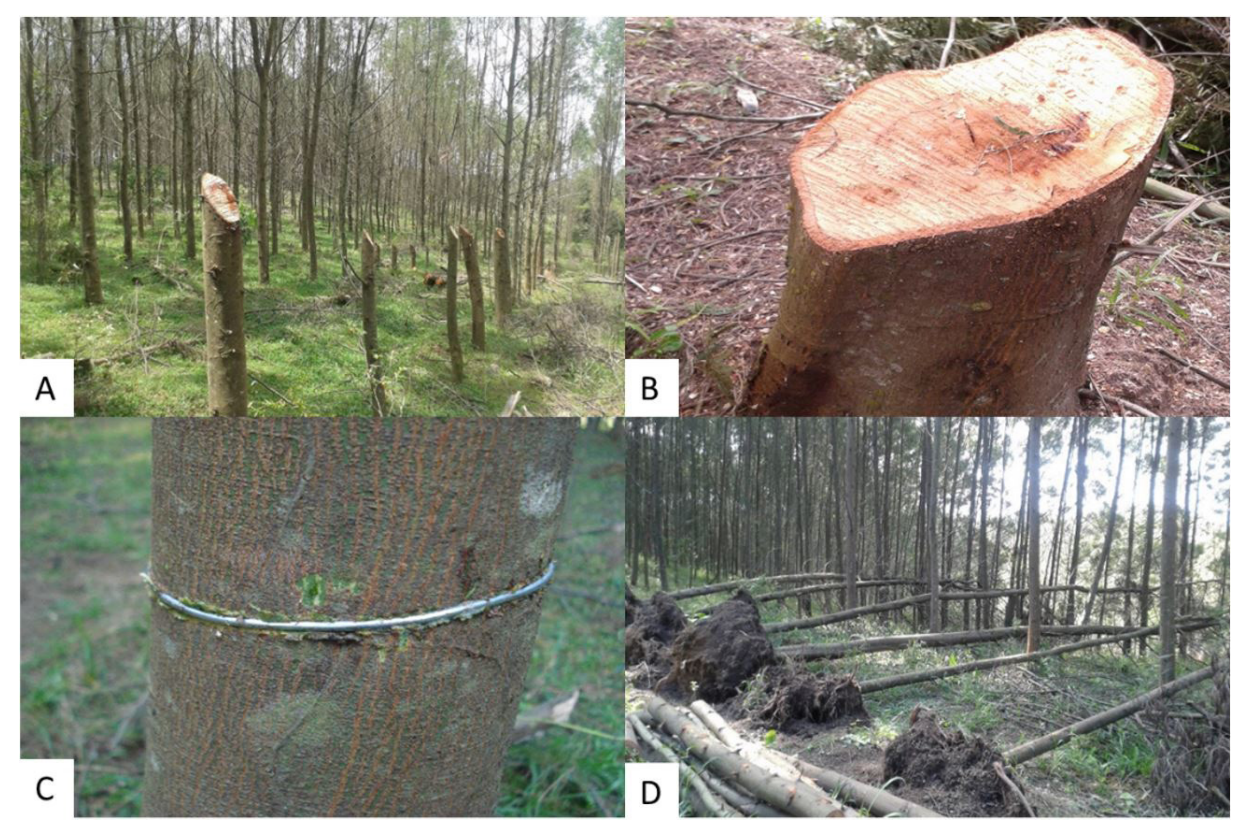

Figura 1 - Tratamentos para resgate de matrizes aplicados em árvores de A. mearnsii De Wildeman.

Figure 1 - Treatments for stock plants rescue applied to $A$. mearnsii De Wildeman trees. Legenda: A) Decepa de árvores a 1,20 m de altura; B) Detalhe da decepa com corte em bisel aos 0,30 $\mathrm{m}$ de altura; C) Torniquete de arame ao redor da casca; D) Inclinação forçada das árvores. 
Engel et al. - Indução de brotações em matrizes de Acacia mearnsii

De Wildeman em relação a idades e quatro estações do ano

O método de decepa consistiu na realização de corte do fuste das árvores nas alturas determinadas, em bisel para evitar acúmulo de água e apodrecimento precoce das cepas (Figura 1A e B). O torniquete consistiu em contornar o tronco com arame do tipo galvanizado cortando a casca e limitando o fluxo de seiva e hormônios, para que estes se concentrassem na base da árvore (Figura 1C). A inclinação forçada foi realizada com o tombamento total da árvore com auxílio de um guincho manual, mas de forma que a raiz fosse parcialmente arrancada do solo e a copa parcialmente podada, visando alterar o balanço hormonal endógeno das árvores (Figura 1D).

As avaliações da indução de brotações foram realizadas aos 90 dias, com as variáveis porcentagem de árvores com brotações, número de brotações por árvore e comprimento médio das três maiores brotações $(\mathrm{cm})$.

\section{Análise estatística}

O delineamento experimental adotado foi o de blocos casualizados com 15 tratamentos, quatro repetições e seis plantas por parcela, distribuídos em esquema fatorial 3x5 (método de indução de brotações e alturas de corte das árvores). Os experimentos tiveram um total de 120 árvores para cada método, por idade, em cada estação do ano, com exceção do método de inclinação. Nesse caso, todos os tratamentos relacionados com alturas foram aplicados na mesma árvore, portanto, com parcela única por bloco, contando assim, com 32 árvores inclinadas em cada experimento. A seleção das matrizes foi realizada de forma aleatória, sendo que que todas as árvores dentro dos blocos foram avaliadas.

Para as análises estatísticas, inicialmente os tratamentos foram avaliadas quanto à sua homogeneidade pelo teste de Bartlett. Para a porcentagem de árvores com brotações, número de brotações por árvore e comprimento médio das três maiores brotações as variâncias mostraram-se homogêneas tiveram as médias dos tratamentos testadas por meio do teste de F. Posteriormente as médias dos tratamentos foram comparadas pelo teste de Scott-Knott ou pelo teste não paramétrico de Friedman.

\section{RESULTADOS E DISCUSSÃO}

\section{Inverno}

No inverno com árvores de três anos não houve interação significativa entre os métodos de induções e as alturas da árvore para nenhuma variável avaliada. A decepa apresentou o maior número de árvores com brotações $(79,17 \%)$, seguida do torniquete $(62,50 \%)$ e da inclinação forçada $(46,67 \%)$. Já as alturas da base da árvore que apresentaram os melhores resultados foram ao 0,60; 1,20 e 2,0 m, com 63,89; 69,44 e 80,56\% de árvores com brotações, respectivamente, não havendo diferença estatística entre esses três tratamentos (Tabela 1).

Em árvores de três anos a decepa novamente apresentou melhores resultados para o número de brotações, com média de 4,90 brotações/árvore, seguido do torniquete $(2,60)$. Já para as alturas da base da árvore, o melhor desempenho foi o corte aos $2 \mathrm{~m}$ com 6,47 brotações/árvore, diferindo significativamente das demais alturas testadas. Para a variável comprimento médio de brotações ocorreu diferença apenas entre os diferentes métodos de indução, em que a decepa e o torniquete foram melhores, comparados com a inclinação $(2,59 ; 3,47$ e 1,65 cm, respectivamente) (Tabela 1).

Em árvores de cinco anos o método de decepa $(83,33 \%)$ e o de torniquete $(78,33 \%)$ produziram mais brotações nas árvores de acácia negra, diferindo esses significativamente ao método de inclinação forçada $(51,67 \%)$. As alturas de corte também não diferiram significativamente em relação à porcentagem de árvores com brotações, com exceção da altura de 0,40 m que apresentou a menor porcentagem de brotações (Tabela 1).

Para número de brotações por árvore, novamente os métodos de decepa e torniquete tiveram melhor desempenho em árvores de cinco anos, com 2,46 e 2,25 brotações, respectivamente, diferindo significativamente do método de inclinação, com apenas 1,48 . Nesse caso a melhor altura foi aos 2,0 m com 3,15 brotações, seguido de 1,20 m com 2,42 e as demais alturas com valores menores que 2,0. Já para a variável comprimento médio das três maiores brotações, o método de decepa não influenciou no número de brotações/árvore. Apenas a altura do corte influenciou o comprimento das brotações, sendo que apenas aos 0,30 m o desempenho foi reduzido, com uma média de 2,96 cm de comprimento de brotações. As demais alturas não diferiram significativamente entre si, com valores superiores a 4,0 (Tabela 1). 
Tabela 1 - Porcentagem de árvores com brotações, número de brotações por árvore e comprimento médio de brotações por árvore de $A$. mearnsii De Wildeman, aos três e cinco anos, em função de diferentes métodos de indução e diferentes alturas aos 90 dias, no inverno.

Table 1 - Percentage of trees with buds, number of buds per tree and average length of shoots per tree of $A$. mearnsii De Wildeman, at three and five years, due to different induction methods and different heights at 90 days in winter.

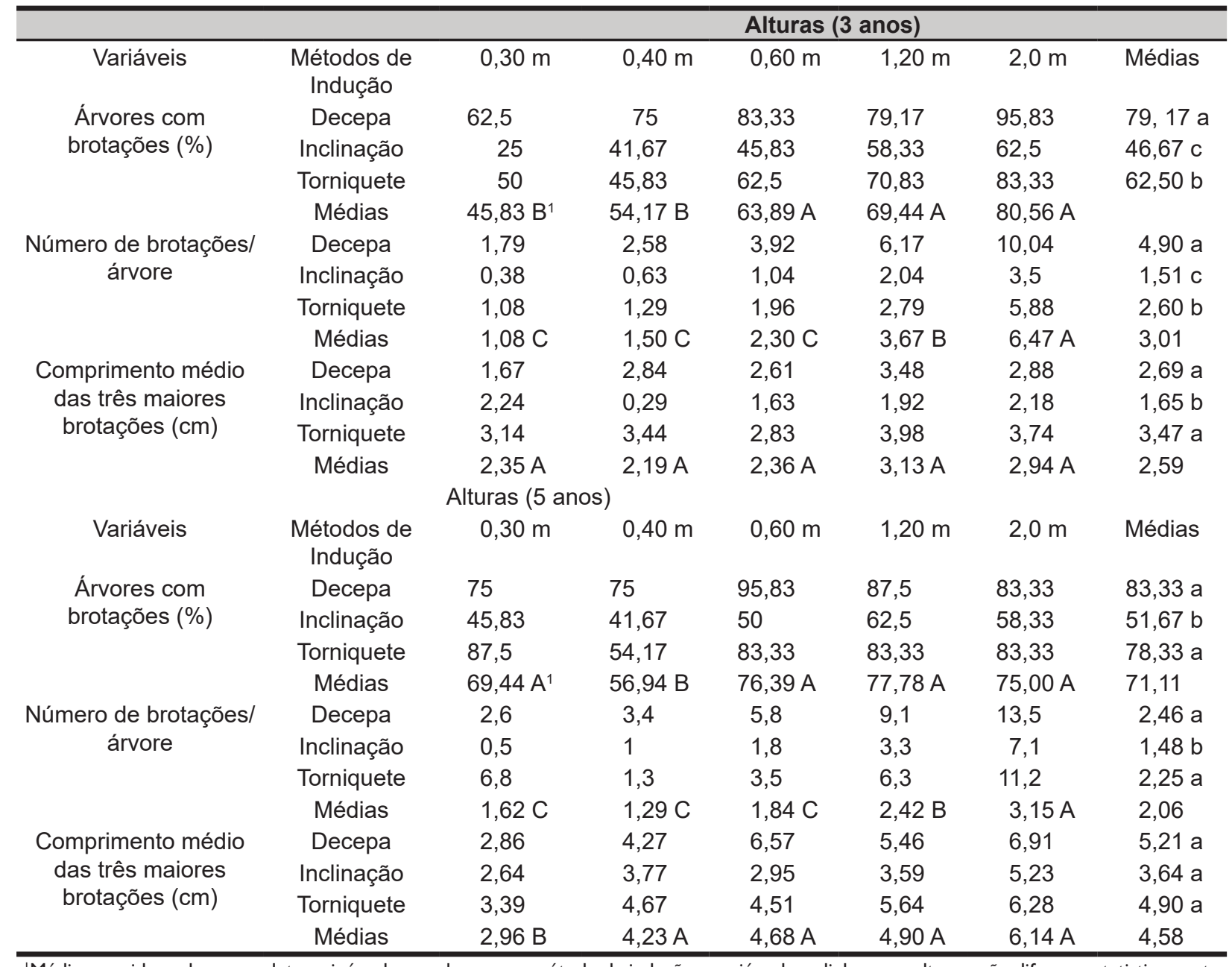

'Médias seguidas pela mesma letra minúscula na coluna, para método de indução e maiúscula na linha, para alturas, não diferem estatisticamente pelo teste de Scott - Knott a I\% de probabilidade.

Na maioria das espécies florestais ocorre um gradiente de juvenilidade ontogenética em direção à base da árvore, ou seja, a maturação aumenta com a proximidade do meristema apical (PIJUT et al. 2011). A maior juvenilidade da região basal das plantas deve-se ao fato de que os meristemas mais próximos da base terem sido formados em uma fase com maior grau de juvenilidade, dada a proximidade com a fase de germinação (HARTMANN et al. 2011). Entretanto, no presente trabalho os melhores resultados para indução das brotações foram observados com o aumento da altura. Isso se deve à indução de brotações ocorrer ao longo do tronco e não somente concentrada na região de indução, logo, quanto maior a altura de indução, maior a área propícia para a formação de brotações epicórmicas e seu desenvolvimento em novas brotações. Isso ocorre devido as necessidades energéticas individuais para a planta se manter, a partir da injúria causada. Quanto maior a parte vegetal mantida, maior a fonte energética para suprimento do metabolismo. Para Johansson (1992), a altura de indução delimita o número de gemas adventícias aptas à rebrota, o que contribui positivamente para a sobrevivência da árvore. Menores alturas de corte podem, também, comprometer a disponibilidade de substâncias de reservas na planta (SAKAI; SAKAI; AKIYAMA 1997).

Como as idades avaliadas são próximas não foram verificadas diferenças de resposta para árvores de três e cinco anos (Tabela 1). Resultados diferentes foram verificados para o número de brotações em cepas de A. mearnsii, na qual a produção de gemas foi maior em árvores com dois anos e menor em árvores de quatro a dez anos, ambas cortadas a 1,5 m de altura (BECK et al., 1998). 
Engel et al. - Indução de brotações em matrizes de Acacia mearnsii

De Wildeman em relação a idades e quatro estações do ano

\section{Primavera}

Em árvores de três anos o torniquete apresentou melhor resposta quando comparados aos demais métodos. Para a inclinação forçada, as árvores não emitiram brotações e com a decepa foram obtidos poucas brotações. Para a variável número de brotações observa-se uma tendência de acréscimo conforme aumenta a altura de indução das brotações com o torniquete (Tabela 2).

Tabela 2 - Porcentagem de árvores com brotações, número de brotações por árvore e comprimento médio das três maiores brotações por árvore de $A$. mearnsii De Wildeman, aos três anos, submetidos a diferentes métodos e diferentes alturas de indução de brotações aos 90 dias, na primavera.

Table 2 - Percentage of trees with buds, number of buds per tree and average length of shoots per tree of $A$. mearnsii De Wildeman, at three years, due to different induction methods and different heights at 90 days in spring.

\begin{tabular}{cccc}
\hline Tratamentos & Árvores com brotações (\%) & $\begin{array}{c}\text { Número de } \\
\text { brotações/ árvore }\end{array}$ & $\begin{array}{c}\text { Comprimento médio das } \\
\text { três maiores brotações }(\mathbf{c m})\end{array}$ \\
\hline Decepa a 0,30 m & $4,17 \mathrm{~cd}^{1}$ & $0,75 \mathrm{def}$ & $0,58 \mathrm{de}$ \\
Decepa a 0,40 m & $12,5 \mathrm{~b}$ & $1,00 \mathrm{~d}$ & $2,50 \mathrm{~cd}$ \\
Decepa a 0,60 m & $8,33 \mathrm{bc}$ & $0,75 \mathrm{def}$ & $0,69 \mathrm{de}$ \\
Decepa a 1,2 m & $4,17 \mathrm{~cd}$ & $0,25 \mathrm{ef}$ & $0,25 \mathrm{de}$ \\
Decepa a 2,0 m & $8,33 \mathrm{bc}$ & $1,50 \mathrm{de}$ & $1,17 \mathrm{de}$ \\
Inclinação a 0,3 m & $0,00 \mathrm{~d}$ & $0,00 \mathrm{f}$ & $0,00 \mathrm{e}$ \\
Inclinação a 0,4 m & $0,00 \mathrm{~d}$ & $0,00 \mathrm{f}$ & $0,00 \mathrm{e}$ \\
Inclinação a 0,6 m & $0,00 \mathrm{~d}$ & $0,00 \mathrm{f}$ & $0,00 \mathrm{e}$ \\
Inclinação a 1,2 m & $0,00 \mathrm{~d}$ & $0,00 \mathrm{f}$ & $0,00 \mathrm{e}$ \\
Inclinação a 2,0 m & $0,00 \mathrm{~d}$ & $0,00 \mathrm{f}$ & $0,00 \mathrm{e}$ \\
Torniquete a 0,3 m & $75,00 \mathrm{a}$ & $2,28 \mathrm{c}$ & $2,81 \mathrm{bc}$ \\
Torniquete a 0,4 m & $75,00 \mathrm{a}$ & $3,22 \mathrm{bc}$ & $5,60 \mathrm{ab}$ \\
Torniquete a 0,6 m & $94,43 \mathrm{a}$ & $4,43 \mathrm{abc}$ & $4,73 \mathrm{ab}$ \\
Torniquete a 1,2 m & $77,78 \mathrm{a}$ & $6,20 \mathrm{ab}$ & $6,41 \mathrm{ab}$ \\
Torniquete a 2,0 m & $79,17 \mathrm{a}$ & $6,25 \mathrm{a}$ & $6,90 \mathrm{a}$ \\
Friedman $\left(X^{2}\right)$ & $48,82^{* *}$ & $48,07^{* *}$ & $46,48^{* *}$ \\
GL & 14 & & \\
\hline
\end{tabular}

'Médias seguidas pela mesma letra minúscula na coluna não diferem estatisticamente pelo teste de Friedman a I\% de probabilidade**. GL = Graus de Liberdade.

Em árvores de cinco anos as maiores porcentagens de árvores com brotações foram verificadas com o método de torniquete $(73,33 \%)$, diferindo significativamente da decepa $(25,83 \%)$ e da inclinação forçada $(14,17 \%)$. As alturas de $0,60,1,20$ e 2,0m apresentaram mais árvores com brotações, com 40,28, 43,06 e 50,00\%, respectivamente. Com o efeito da interação entre os fatores os métodos torniquete a $0,60,1,20$ e 2,0m foram superiores e diferiram dos demais tratamentos com 95,83, 75,00 e 95,83\%, respectivamente (Tabela 3).

Tabela 3 - Porcentagem de árvores com brotações, número de brotações por árvore e comprimento médio de brotações por árvore de $A$. mearnsii De Wildeman, aos cinco anos, em função de diferentes métodos de indução e alturas aos 90 dias, na primavera.

Table 3 - Percentage of trees with buds, number of buds per tree and average length of shoots per tree of $A$. mearnsii De Wildeman, at five years, due to different induction methods and different heights at 90 days in spring.

\begin{tabular}{cccccccc}
\hline \multirow{2}{*}{ Variáveis } & Métodos de & \multicolumn{7}{c}{ Alturas } \\
\cline { 3 - 8 } & Indução & $\mathbf{0 , 3 0} \mathbf{~ m}$ & $\mathbf{0 , 4 0} \mathbf{~}$ & $\mathbf{0 , 6 0} \mathbf{~ m}$ & $\mathbf{1 , 2 0} \mathbf{~ m}$ & $\mathbf{2 , 0} \mathbf{~ m}$ & Médias \\
\hline Árvores com & Decepa & $16,67 \mathrm{bA}$ & $25,00 \mathrm{bA}$ & $12,50 \mathrm{bA}$ & $37,50 \mathrm{bA}$ & $37,50 \mathrm{bA}$ & $25,83 \mathrm{~b}$ \\
brotações (\%) & Inclinação & $12,50 \mathrm{bA}$ & $12,50 \mathrm{bA}$ & $12,50 \mathrm{bA}$ & $16,67 \mathrm{bA}$ & $16,67 \mathrm{bA}$ & $14,17 \mathrm{c}$ \\
& Torniquete & $54,17 \mathrm{aB}$ & $45,83 \mathrm{aB}$ & $95,83 \mathrm{aA}$ & $75,00 \mathrm{aA}$ & $95,83 \mathrm{aA}$ & $73,33 \mathrm{a}$ \\
& Médias & $27,78 \mathrm{~B}$ & $27,78 \mathrm{~B}$ & $40,28 \mathrm{~A}$ & $43,016 \mathrm{~A}$ & $50,00 \mathrm{~A}$ & 37,78 \\
Número de & Decepa & $0,29 \mathrm{aA}$ & $0,62 \mathrm{aA}$ & $0,54 \mathrm{bA}$ & $0,83 \mathrm{bA}$ & $1,54 \mathrm{bA}$ & $0,77 \mathrm{~b}$ \\
brotações/ árvore & Inclinação & $0,25 \mathrm{aA}$ & $0,29 \mathrm{aA}$ & $0,37 \mathrm{bA}$ & $0,67 \mathrm{bA}$ & $0,75 \mathrm{bA}$ & $0,47 \mathrm{~b}$ \\
& Torniquete & $1,21 \mathrm{aC}$ & $1,67 \mathrm{aC}$ & $2,75 \mathrm{aC}$ & $5,3 \mathrm{aB}$ & $8,42 \mathrm{aA}$ & $3,88 \mathrm{a}$ \\
& Médias & $0,58 \mathrm{C}$ & $0,86 \mathrm{C}$ & $1,22 \mathrm{C}$ & $2,29 \mathrm{~B}$ & $3,57 \mathrm{~A}$ & 1,7 \\
Comprimento & Decepa & 2,42 & 3,65 & 3,83 & 7,88 & 6,58 & $4,87 \mathrm{a}$ \\
médio das três & Inclinação & 1,04 & 0,50 & 1,00 & 0,69 & 0,25 & $0,69 \mathrm{~b}$ \\
maiores brotações & Torniquete & 6,86 & 4,18 & 4,59 & 5,60 & 8,96 & $6,03 \mathrm{a}$ \\
(cm) & Médias & $3,44 \mathrm{~A}$ & $2,77 \mathrm{~A}$ & $3,14 \mathrm{~A}$ & $4,72 \mathrm{~A}$ & $5,26 \mathrm{~A}$ & 3,90 \\
\hline
\end{tabular}

'Médias seguidas pela mesma letra minúscula na coluna e maiúscula na linha não diferem estatisticamente pelo teste de Scott - Knott a I\% de probabilidade. 
A prática de uso do torniquete ao redor da casca é semelhante a técnica de anelamento, que provoca o aumento da concentração de auxina e carboidratos acima da região interceptada e citocininas abaixo (SARTORI; ILHA, 2005; HARTMANN et al., 2011). Dessa forma, uma menor concentração momentânea de auxina na região inferior ao anelamento pode ter ocasionado um decréscimo do balanço auxina/citocinina, fator esse, que pode ter sido responsável pela maior ocorrência de brotações.

Para o número de brotações, em árvores de cinco anos, o método de torniquete diferiu significativamente dos demais, com maior número de brotações formadas $(3,88)$. A maior formação de brotações ocorreu com a altura de 2,0 m (3,57 brotações/árvore), diferindo significativamente das demais alturas. O melhor tratamento testado foi com torniquete ao redor da casca aos 2,0 m de altura com 8,42 brotações/árvore. Já para o comprimento médio das três maiores brotações a decepa e o torniquete foram os que apresentaram os melhores resultados, com 4,87 e 6,03cm de comprimento, respectivamente (Tabela 3).

\section{Verão}

Aos três anos todas as variáveis avaliadas apresentaram resultados superiores com o método de torniquete em todas as alturas e pelo método de decepa na altura de 2,0 m. O mesmo ocorreu para a idade de cinco anos, com porcentagem de árvores com brotações atingindo 91,67\% no torniquete. Aos cinco anos, o número de brotações e comprimento médio das três maiores brotações, os melhores resultados foram obtidos com o torniquete a 1,20 e 2,0 m (11,06 e 16,43 brotações /árvore e 9,90 e 9,81 cm, respectivamente) (Tabela 4). A altura de corte de algumas espécies arbóreas é um fator que pode restringir a capacidade de rebrota das cepas. Alturas de corte próximas ao nível do solo favorecem o ataque de fungos degradadores da madeira e, ao mesmo tempo, cepas com alturas elevadas podem reduzir o vigor e o crescimento das brotações (SHACKLETON, 2000).

Tabela 4 - Porcentagem de árvores com brotações, número de brotações por árvore e comprimento médio das três maiores brotações por árvore de $A$. mearnsii De Wildeman, aos três e cinco anos, submetidos a diferentes métodos e diferentes alturas de indução de brotações aos 90 dias, no verão.

Table 4 - Percentage of trees with buds, number of buds per tree and average length of shoots per tree of $A$. mearnsii De Wildeman, at three and five years, due to different induction methods and different heights at 90 days in summer.

\begin{tabular}{|c|c|c|c|c|c|c|}
\hline \multirow[t]{2}{*}{ Tratamentos } & \multicolumn{2}{|c|}{ Árvores com brotações (\%) } & \multicolumn{2}{|c|}{$\begin{array}{c}\text { Número de brotações/ } \\
\text { árvore }\end{array}$} & \multicolumn{2}{|c|}{$\begin{array}{l}\text { Comprimento médio das } \\
\text { três maiores brotações }(\mathrm{cm})\end{array}$} \\
\hline & 3 anos & 5 anos & 3 anos & 5 anos & 3 anos & 5 anos \\
\hline Decepa a 0,30 m & $8,33 \mathrm{c}$ & $12,5 \mathrm{c}$ & $0,25 \mathrm{de}$ & 1 ef & $0,13 \mathrm{c}$ & $1,44 \mathrm{de}$ \\
\hline Decepa a 0,40 m & $4,17 \mathrm{c}$ & $16,67 \mathrm{c}$ & $0,25 \mathrm{de}$ & $0,63 \mathrm{f}$ & $0,13 \mathrm{c}$ & $1,48 \mathrm{de}$ \\
\hline Decepa a 0,60 m & $8,33 \mathrm{c}$ & $16,67 \mathrm{c}$ & $2,5 \mathrm{~cd}$ & 1,75 def & $0,5 \mathrm{c}$ & $1,44 \mathrm{e}$ \\
\hline Decepa a 1,2 m & $50 \mathrm{~b}$ & $50 \mathrm{~b}$ & $3,08 \mathrm{bc}$ & 2,56 cde & $2,07 b$ & $3,26 \mathrm{~cd}$ \\
\hline Decepa a 2,0 m & $62,5 a b$ & 54,17 b & 7,81 a & $5,56 \mathrm{c}$ & $2,5 a b$ & $4 \mathrm{bcd}$ \\
\hline Inclinação a 0,3 m & $12,5 \mathrm{c}$ & $0 \mathrm{c}$ & $0,5 \mathrm{de}$ & $0 \mathrm{f}$ & $0,25 \mathrm{c}$ & $0 \mathrm{e}$ \\
\hline Inclinação a 0,4 m & $0 \mathrm{c}$ & $4,17 \mathrm{C}$ & $0 \mathrm{e}$ & $0,25 \mathrm{f}$ & $0 \mathrm{c}$ & 0,69 e \\
\hline Inclinação a 0,6 m & $4,17 \mathrm{c}$ & $4,17 \mathrm{c}$ & $0,25 \mathrm{de}$ & $0,5 \mathrm{f}$ & $0,13 \mathrm{c}$ & $0,5 \mathrm{e}$ \\
\hline Inclinação a 1,2 m & $4,17 \mathrm{C}$ & $4,17 \mathrm{C}$ & 0,5 de & 1,25 ef & $0,13 \mathrm{c}$ & $0,38 \mathrm{e}$ \\
\hline Inclinação a 2,0 m & $8,33 \mathrm{c}$ & $8,33 \mathrm{c}$ & $1 \mathrm{de}$ & $0,5 \mathrm{f}$ & $0,63 \mathrm{c}$ & $1 \mathrm{de}$ \\
\hline Torniquete a $0,3 \mathrm{~m}$ & $91,67 a b$ & 91,67 a & $4,42 a b$ & $3,58 \mathrm{~cd}$ & $3,6 a b$ & $4,1 \mathrm{~cd}$ \\
\hline Torniquete a $0,4 \mathrm{~m}$ & 95,83 a & $87,5 a b$ & $4,43 a b$ & $4,6 \mathrm{bc}$ & $3,59 a b$ & $5,97 \mathrm{abc}$ \\
\hline Torniquete a $0,6 \mathrm{~m}$ & $91,67 a b$ & 87,5 a & $6,52 a b$ & $6,15 a b c$ & 6,59 a & $6,18 \mathrm{abc}$ \\
\hline Torniquete a 1,2 m & $94,44 a b$ & 91,67 a & 8,29 a & $11,06 a b$ & 5,83 a & 9,9 a \\
\hline Torniquete a 2,0 m & $75 a b$ & 91,67 a & $15,58 a b$ & 16,43 a & $8,6 a b$ & $9,81 \mathrm{ab}$ \\
\hline Friedman $\left(X^{2}\right)$ & $45,43^{* *}$ & $46,24^{* *}$ & $44,03^{* *}$ & $42,88^{* *}$ & $43,71^{* *}$ & $33,36^{* *}$ \\
\hline GL & 14 & & & & & \\
\hline
\end{tabular}

'Médias seguidas pela mesma letra minúscula na coluna não diferem estatisticamente pelo teste de Friedman a $1 \%$ de probabilidade**. $\mathrm{GL}=$ Graus de Liberdade.

Com o uso do torniquete o estresse ocorre em virtude da interrupção do transporte de fotossintetizados e outros metabólicos orgânicos das partes mais altas para as mais baixas da planta, realizado por elementos e células crivadas, situados na região do floema (SANTOS et al., 2014). O torniquete não causa a morte da árvore, pois não interrompe o transporte acrópeto do xilema, deixando à árvore apta a indução de brotações por mais tempo. 
Engel et al. - Indução de brotações em matrizes de Acacia mearnsii

De Wildeman em relação a idades e quatro estações do ano

\section{Outono}

Para árvores com três anos, no outono as alturas de 0,60, 1,20 e 2,0 m diferiram significativamente das demais com porcentagens de árvores com brotações de 70,83, 79,17 e 83,33\%, respectivamente. A altura de 2,0 $\mathrm{m}$ foi a que apresentou o maior número de brotações por árvore $(10,54)$, diferindo significativamente das demais alturas. Houve diferença entre o comprimento médio das três maiores brotações apenas entre os métodos de indução, sendo o torniquete superior aos demais com 3,73 cm (Tabela 5).

Tabela 5 - Porcentagem de árvores com brotações, número de brotações por árvore e comprimento médio de brotações por árvore de $A$. mearnsii De Wildeman, aos três e cinco anos, em função de diferentes métodos de indução e diferentes alturas aos 90 dias, no outono.

Table 5 - Percentage of trees with buds, number of buds per tree and average length of shoots per tree of $A$. mearnsii De Wildeman, at three and five years, due to different induction methods and different heights at 90 days in autumn.

\begin{tabular}{|c|c|c|c|c|c|c|c|}
\hline \multirow{2}{*}{ Variáveis } & \multirow{2}{*}{$\begin{array}{l}\text { Métodos de } \\
\text { indução }\end{array}$} & \multicolumn{6}{|c|}{ Alturas (3 anos) } \\
\hline & & $0,30 \mathrm{~m}$ & $0,40 \mathrm{~m}$ & $0,60 \mathrm{~m}$ & $1,20 \mathrm{~m}$ & $2,0 \mathrm{~m}$ & Médias \\
\hline \multirow{4}{*}{$\begin{array}{l}\text { Árvores com } \\
\text { brotações (\%) }\end{array}$} & Decepa & 62,5 & 50 & 62,5 & 75 & 83,33 & $66,67 \mathrm{a}$ \\
\hline & Inclinação & 25 & 54,17 & 66,67 & 75 & 79,17 & $60,00 \mathrm{a}$ \\
\hline & Torniquete & 62,5 & 75 & 83,33 & 87,5 & 87,5 & $79,17 \mathrm{a}$ \\
\hline & Médias & $50,00 \mathrm{~B}$ & $59,72 \mathrm{~B}$ & $70,83 \mathrm{~A}$ & $79,17 \mathrm{~A}$ & $83,33 \mathrm{~A}$ & 68,61 \\
\hline \multirow{4}{*}{$\begin{array}{l}\text { Número de } \\
\text { brotações/ } \\
\text { árvore }\end{array}$} & Decepa & 3,65 & 2,18 & 4,27 & 7,15 & 11,42 & $5,73 \mathrm{a}$ \\
\hline & Inclinação & 2,33 & 5,23 & 5,34 & 6,93 & 9,11 & $5,79 a$ \\
\hline & Torniquete & 2,54 & 4,74 & 5,1 & 6,23 & 11,08 & $5,94 \mathrm{a}$ \\
\hline & Médias & $2,84 \mathrm{~B}$ & $4,05 \mathrm{~B}$ & $4,90 \mathrm{~B}$ & 6,77 A B & $10,54 \mathrm{~A}$ & 5,82 \\
\hline \multirow{4}{*}{$\begin{array}{l}\text { Comprimento } \\
\text { médio das } \\
\text { três maiores } \\
\text { brotações }(\mathrm{cm})\end{array}$} & Decepa & 2,05 & 1,28 & 2,67 & 2,85 & 4,05 & $2,58 \mathrm{~b}$ \\
\hline & Inclinação & 2,19 & 1,43 & 2,13 & 1,51 & 2,8 & $2,01 \mathrm{~b}$ \\
\hline & Torniquete & 2,11 & 2,69 & 4,18 & 4,56 & 5,09 & $3,72 \mathrm{a}$ \\
\hline & Médias & $2,12 \mathrm{~A}$ & $1,80 \mathrm{~A}$ & $2,99 \mathrm{~A}$ & $2,97 \mathrm{~A}$ & $3,98 \mathrm{~A}$ & 2,77 \\
\hline \multirow{2}{*}{ Variáveis } & Métodos de & \multicolumn{6}{|c|}{ Alturas (5 anos) } \\
\hline & indução & $0,30 \mathrm{~m}$ & $0,40 \mathrm{~m}$ & $0,60 \mathrm{~m}$ & $1,20 \mathrm{~m}$ & $2,0 \mathrm{~m}$ & Médias \\
\hline \multirow{4}{*}{$\begin{array}{l}\text { Árvores com } \\
\text { brotações (\%) }\end{array}$} & Decepa & 77,78 & 62,5 & 66,67 & 83,33 & 83,33 & $74,72 \mathrm{a}$ \\
\hline & Inclinação & 29,17 & 20,83 & 29,17 & 58,33 & 50 & $37,50 \mathrm{~b}$ \\
\hline & Torniquete & 70,83 & 75 & 83,33 & 79,17 & 87,5 & $79,17 \mathrm{a}$ \\
\hline & Médias & $59,26 \mathrm{~B}$ & $52,78 \mathrm{~B}$ & 59,72 B & $73,61 \mathrm{~A}$ & $73,61 \mathrm{~A}$ & 63,8 \\
\hline \multirow{4}{*}{$\begin{array}{l}\text { Número de } \\
\text { brotações/ } \\
\text { árvore }\end{array}$} & Decepa & $3,53 \mathrm{aB}$ & $3,92 \mathrm{aB}$ & $5,70 \mathrm{aB}$ & $7,30 \mathrm{aB}$ & 14,36 aA & $6,96 \mathrm{a}$ \\
\hline & Inclinação & $1,58 \mathrm{aA}$ & $1,50 \mathrm{aA}$ & $1,83 \mathrm{bA}$ & $3,42 \mathrm{bA}$ & $5,06 \mathrm{bA}$ & $2,68 \mathrm{~b}$ \\
\hline & Torniquete & $3,61 \mathrm{aC}$ & $3,35 \mathrm{aC}$ & $4,67 \mathrm{abBC}$ & $7,52 \mathrm{aB}$ & $16,90 \mathrm{aA}$ & $7,21 \mathrm{a}$ \\
\hline & Médias & $2,91 \mathrm{C}$ & $2,92 \mathrm{C}$ & $4,07 \mathrm{C}$ & $6,08 \mathrm{~B}$ & $12,11 \mathrm{~A}$ & 5,61 \\
\hline \multirow{4}{*}{$\begin{array}{l}\text { Comprimento } \\
\text { médio das } \\
\text { três maiores } \\
\text { brotações }(\mathrm{cm})\end{array}$} & Decepa & 3,52 & 3,12 & 2,43 & 3,78 & 4,03 & $3,38 \mathrm{~b}$ \\
\hline & Inclinação & 0,75 & 1,44 & 0,81 & 1,22 & 2,76 & $1,39 \mathrm{c}$ \\
\hline & Torniquete & 3,37 & 3,73 & 3,96 & 5,1 & 7,31 & $4,69 a$ \\
\hline & Médias & $2,54 \mathrm{~B}$ & $2,76 \mathrm{~B}$ & $2,40 \mathrm{~B}$ & $3,37 \mathrm{~B}$ & $4,70 \mathrm{~A}$ & 3,15 \\
\hline
\end{tabular}

'Médias seguidas pela mesma letra minúscula na coluna e maiúscula na linha não diferem estatisticamente pelo teste de Scott - Knott a $5 \%$ e $\%$ de probabilidade.

Para árvores com cinco anos os métodos de decepa e torniquete apresentaram as maiores porcentagens de árvores com brotações $(74,72$ e 79,17, respectivamente) e foram superiores a inclinação (37,50\%). As alturas de 1,20 e 2,0 m também foram superiores as demais, ambas com $73,61 \%$. Para o número de brotações por árvore houve interação entre os fatores método de indução e altura, sendo que para decepa e torniquete a altura de 2,0 $\mathrm{m}$ foi superior, e para inclinação forçada as menores alturas, de 0,30 e 0,40 m, apresentaram melhores resultados. Para o comprimento médio das três maiores brotações, a altura de 2,0 m também apresentou resultados superiores $(4,70 \mathrm{~cm})$, assim como o método de torniquete $(4,69 \mathrm{~cm})$, diferindo significativamente da decepa $(3,38 \mathrm{~cm}) \mathrm{e}$ da inclinação $(1,39 \mathrm{~cm})$ (Tabela 5).

A altura de corte delimita o número de brotações adventícias aptas à rebrota, o que contribui positivamente para a sobrevivência da cepa. Menores alturas de corte podem, também, comprometer a disponibilidade de substâncias de reservas na planta (JOHANSSON, 1992). Contudo, o tempo em que a cepa dependerá das substâncias de reserva alocadas no sistema radicular, até estabelecer brotações 
fotossinteticamente ativas, poderá ser um fator crítico para sua sobrevivência (HARDESTY et al., 1988). Em contrapartida, quando o corte é realizado na época ideal, variável entre espécies, pode promover uma maximização da capacidade de rebrota das cepas (CEULEMANS et al., 1996). Isso explica as diferentes respostas observadas no presente trabalho nas diferentes épocas do ano, quanto a sobrevivência e número de brotações.

No outono também ocorreu uma tendência de melhor indução de brotações, com o aumento da altura de indução na árvore, principalmente para número de brotações por árvore. E neste caso, os resultados não diferiram entre as idades de três e cinco anos, embora não tenham sido comparados estatisticamente (Tabela 5).

\section{CONCLUSÃO}

O torniquete apresenta-se como o método mais eficiente para a indução de brotações na primavera, verão e outono e no inverno a decepa. As alturas de 1,20 e 2,0 m proporcionam maior número de brotações por árvore. Árvores de três e cinco anos não diferem na porcentagem de árvores com brotações e na quantidade de brotações por árvore.

\section{REFERÊNCIAS}

ALFENAS, A. C.; ZAUZA, E. A. V.; MAFIA, R. G.; ASSIS, T. F. de. Clonagem e Doenças do Eucalipto. Viçosa: UFV, 2004. $442 \mathrm{p}$.

BACCARIN, F. J. B.; BRONDANI, G. E.; ALMEIDA, L. V. DE; VIEIRA, I. G.; OLIVEIRA, L. S. de; ALMEIDA, M. de Vegetative rescue and cloning of Eucalyptus benthamii selected adult trees. New Forests, v. 46, p. 465-483, 2015.

BECK, S. L.; DUNLOP, R.; VAN STADEN, J. Rejuvenation and micropropagation of adult Acacia mearnsii using coppice material. Plant Growth Regulation, New York, v. 26, p. 149-153, 1998.

BORGES JUNIOR, N.; MARTINS-CORDER, M. P.;. SOBROSA, R. C.; SANTOS, E. M. DE. Rebrota de cepas de árvores adultas de acácia-negra (Acacia mearnsii De Wild.). Revista Árvore, Viçosa, v. 28, n. 4, p. 611-615, 2004.

CEULEMANS, R.; MCDONALD, A. J. S.; PEREIRA, J. S. A comparison among eucalypt, poplar and willow characteristics with particular reference to a coppice, growth-modelling approach. Biomass and Bioenergy, Amsterdan, v. 11, n. 2-3, p. 215-231, 1996.

DISARZ, R.; MARTINS-CORDER, M. P. Multiplicação de gemas axilares de Acacia mearnsii De Wild. sob diferentes meios de cultura. Revista Árvore, v. 33, n. 4, p.599-606, 2009.

ENGEL, M. L.; HIGA, A. R.; ALCANTARA, G. B. de; FLÔRES JUNIOR, P. C.; SOARES, I. D. enraizamento de miniestacas de diferentes clones de Acacia mearnsii De Wildeman com aplicação de AIB. Revista Espacios, v. 38, n. 23, p. 1-8, 2017.

FOWLER, J. A. P.; CURCIO, G. R.; RACHWAL, M. F. G.; DEDECEK, R. A.; SIMON, A. A. Germinação e vigor de sementes de Acacia mearnsii De Wild. coletadas em diferentes povoamentos do Estado do Rio Grande do Sul. Colombo: Embrapa- CNPF, 1999. 4 p. (Comunicado técnico, 39).

HARDESTY, L. H.; BOX, T. W.; MALECHEK, J. C. Season of cutting affects biomass production by coppicing browse species of the Brazilian caatinga. Journal of Range Management, Arizona, v. 41, n. 6, p. 477-480, 1988.

HARTMANN, H. T.; KeSTER, D. E.; DAVIS JUNIOR, F. T.; GENEVE, R. L. Plant propagation: principles e practices. 8. ed. Boston: Prentice Hall, 2011. 915 p.

IBÁ - INDÚSTRIA BRASILEIRA DE ÁRVORES. Relatório Anual 2016: ano base 2015. São Paulo: IBÁ, 2016. 100 p.

INMET - INSTITUTO NACIONAL DE METEREOLOGIA. Boletins climáticos para o Rio Grande do Sul - Ano 2015 e 2016. Disponível em: < http://www.inmet.gov.br/portal/index.php?r=clima/boletimRioGrandeDoSul $>$. Acesso em: 01 jun. 2018.

JOHANSSON, T. Sprouting of 2- to 5-year-old birches (Betula pubescens Ehrh. and Betula pendula Roth) in relation to stump height and felling time. Forest Ecology and Management, Amsterdam, v. 53, n. 1-4, p. 263-281, 1992 
Engel et al. - Indução de brotações em matrizes de Acacia mearnsii

De Wildeman em relação a idades e quatro estações do ano

LIU, H.; GAO, Y.; SONG, X.; MA, Q.; ZHANG, J. PEI, D. A novel rejuvenation approach to induce endohormones and improve rhizogenesis in mature Juglans tree. Plant Methods, v. 14, n. 1, p. 1-14, 2018.

LUOGA, E. J.; WITKOWSKI, E. T. F.; BALKWILL, K. Regeneration by coppicing (resprouting) of miombo (African savanna) trees inrelation to land use. Forest Ecology and Management, Amsterdam, v.189, p.23-35, 2004.

PERRANDO, E. R.; MARTINS CORDER, M. P. Rebrota de cepas de Acacia mearnsii em diferentes idades, épocas do ano e alturas de corte. Pesquisa Agropecuária Brasileira, Brasília, v. 41, n. 4, p. 555-562, 2006.

PIJUT, P. M.; WOWSTE, K. E.; MICHLER, C. H. Promotion of adventitious root formation of difficult-to-root hardwood tree species. Horticultural Reviews, v. 38, p. 213-251, 2011.

RIO GRANDE DO SUL. Secretaria de Agricultura e Abastecimento. Macrozoneamento agroecológico e econômico do Estado do Rio Grande do Sul. Porto Alegre: Secretaria de Agricultura e Abastecimento, 1994. 307 p.

SAKAI, A.; SAKAI, S. A test for the resource remobilization hypothesis: tree sprouting using carbohydrates from above-ground parts. Annals of Botany, v. 82, p. 213-216, 1998.

SAKAI, A.; SAKAI, S.; AKIYAMA, F. Do sprouting tree species on erosion-prone sites carry large reserves of resources? Annals of Botany, Inglaterra, v. 79, n. 6, p. 625-630, 1997.

SANTOS, D.; SIQUEIRA, D. L.; SALOMÃO, L. C. C.; CECON, P. R.; OLIVEIRA, G. P.; MACHADO, D. L. M.; ZUCOLOTO, M. Teores de carboidratos e fluorescência da clorofila $\alpha$ em folhas de limeiras ácidas "Tahiti" submetidas ao anelamento e incisão anelar de ramos. Ciência Rural, Santa Maria, v. 44, n. 10, p. 1725-1731, 2014.

SARTORI, I. A.; ILHA, L. L. H. Anelamento e incisão anelar em fruteiras de caroço. Ciência Rural, Santa Maria, v. 35, n. 3, p. 724-729, 2005.

SHACKLETON, C. M. Stump size and the number of coppice shoots for selected savanna tree species. South African Journal of Botany, South Africa, v. 66, n. 2, p. 124-127, 2000.

STUEPP, C. A.; BITENCOURT, J de; WENDLING, I.; KOEHLER, H. S.; ZUFFELLATO-RIBAS, K. C. Indução de brotações epicórmicas por meio de anelamento e decepa em erva-mate. Ciência Florestal, Santa Maria, v. 26, n. 3, p. 1009-1022, 2016.

WENDLING, I.; TRUEMAN, S. J.; XAVIER, A. Maturation and related aspects in clonal forestry - Part I: concepts, regulation and consequences of phase change. New Forests, v. 45, p. 449-471, 2014.

Recebido em: 29/11/2017

Aceito em: 20/09/2018 